Research Letter

\title{
THz therapy effects in patients of different age groups with angina
}

\author{
Svetlana S. Parshina, Tatyana N. Afanasyeva, Tatyana V. Golovacheva, Vyacheslav F. Kirichuk, \\ Alexander V. Vodolagin
}

Saratov State Medical University n.a. V.I. Razumovsky, Saratov, Russia

Received 25 July 2013, Revised 25 August 2013, Accepted 25 September 2013

(C) 2013, Parshina S.S., Afanasyeva T.N., Golovacheva T.V., Kirichuk V.F., Vodolagin A.V.

(C) 2013, Russian Open Medical Journal

Abstract: There had been studied the effect of THz therapy of nitrogen oxide (NO) waves in effort angina at 36 middle-aged patients and at 20 patients of a certain age. Antianginal effect in the both groups did not differ. At the middle-aged patients (46-59 years) there had been revealed an increase of anticoagulant blood potency, at the elderly patients (60-74 years) - a decrease of natural procoagulant activity.

Keywords: THz therapy, angina, age

Cite as Parshina SS, Afanasyeva TN, Golovacheva TV, Kirichuk VF, Vodolagin AV. THz therapy effects in patients of different age groups with angina. Russian Open Medical Journal 2013; 2: 0411.

Correspondence to Prof. Svetlana S. Parshina. Address: Saratov State Medical University, 121, Bolshaya Kazachya str., Saratov, 410012, Russia. E-mail: parshinasvetlana@rambler.ru

\section{Introduction}

Age sensitivity of patients with angina to different therapeutic methods, as drug as non-drug, is not enough studied. At the same time, the change of sensitivity to treatment depending on age, can cause an effectiveness or ineffectiveness of the treatment.

$\mathrm{THz}$ therapy is a new non-drug method of treatment which includes the usage of $\mathrm{THz}$ electromagnetic radiation (EMR) [1]. Today $\mathrm{THz}$ radiation of nitrogen oxide (NO) molecular spectrum $(150.176 \ldots 150.644 \mathrm{GHz})$ (THz-therapy-NO) is widely used in cardiology, its influence, probably, as we can see from the experiments [2], is realized by NO cycle modulation. Positive effect of EMR THz-NO on the patients with a cardiovascular pathology does not cause any doubts, as the set of experiments displayed a decrease of angina episodes, heart rate and arterial tension (systolic and diastolic) under the exposure of THz-therapy-NO, in the patients with stable and unstable angina, effect on hemostasis system and rheological blood properties $[3,4]$. At this stage of the research we concentrate our attention on the detalization of $\mathrm{THz}$ waves effects, which can let perform an individual irradiation parameters in clinical practice. On the base of the given experiments there had been revealed that in high-sensitive patients a shorter radiation time-mode should be used [3], at chronic DIC syndrome - 7 sets instead of 10 is enough [5]. There had not been fixed differences in antianginal effect of $\mathrm{THz}$ waves in men and women with angina [6], but antihypertensive influence of EMR THz-NO is more evident in men.

The given study aimed to study age sensitivity to THz-therapyNO in patients with effort angina of III-IV f.c.

\section{Material and Methods}

56 patients with effort angina of III-IV f.c. had been examined; they had been exposed by EMR THz-NO on the background of a general drug therapy (aspirin, $\beta$-adrenoblocker, nitrates and etc.). The patients had been divided into: the group of middle-ageв persons (46-59 years) and the elderly patients (60-74 years) (according to WHO classification). The I group included 36 patients, the II group - 20 patients.

The groups were comparable at sex, diagnosis, severity of the initial state, myocardial infarction episode, arterial hypertension, blood circulation and rhythm defects and drug therapy.

EMR THz-NO exposure had been performed with the help of a portable generator. An intermittent irradiation time-mode «3/15» had been used (3-minute radiation, 21-minute pause, course duration - 21 minutes). The transmission delivers $500 \mu \mathrm{W}$, irradiator had been located $4 \mathrm{~cm}$ above the metasternum, the power density was $17.4 \mu \mathrm{W} / \mathrm{cm}^{2}$. Irradiation course -10 sets.

An antianginal treatment effect and dynamics of hemostasis system parameters had been estimated. An antianginal treatment effect was estimated in points according to a relative change of the numbers of angina episodes per day and daily nitroglycerin maintenance [3]. Clinical efficiency had been considered high (excellent) at a total elimination of angina episodes (3 points), well - at a decrease of throes and daily nitroglycerin maintenance to $75 \%$ and more from the initial level ( 2 points). At the decrease of anginal pain episodes and daily nitroglycerin maintenance in the range of $50-75 \%$ the effect was estimated as moderate ( 1 point). The absence of an antianginal effect was determined as 0 points, recrudescence -1 point. 
The research of procoagulantive hemostasis system component included a determination of activated partial thromboplastin time (APTT, sec.), activated time of plasma recalcification (ATR, sec.), prothrombin time (PT, sec.) and fibrinogen ( $F G, g / l)$ concentration by consistent gravimetric method by R.A. Rutberg (1961). To estimate an anticoagulative hemostasis system potency antithrombin-III activity had been studied (At-III, \%) with the use of kits by «Технология-Стандарт» by U. Abildgaard et.al. (1970). Fibrinolytic activity of plasma was estimated by XIla-kallikrein-dependent euglobulin fibrinolysis (EF, $\min )$.

\section{Results}

In the group with the middle-aged patients there were people of $52.9 \pm 0.8$ years, in the group of elderly age $-65.5 \pm 0.7$ years $(p<0.05)$.

On the background of combinated (drug and THz-therapy) there had been noted a statistically valid decrease of the numbers of angina episodes in both groups: in the I group - from 7.48 \pm 1.71 to $0.56 \pm 0.13$ episodes per day before and after treatment $(p<0.05)$, in the II group - from $5.69 \pm 0.63$ to $0.25 \pm 0.09$ episodes per day $(p<0.05)$. At the dismissal from hospital the numbers of angina episodes in both groups did not differ $(p>0.05)$. So, there had not been revealed age differences in sensitivity to antianginal effect of $\mathrm{THz}$ waves.

Analyze of hemostasis system parameters shown that in different age groups there were differences in sensitivity of separate clotting components to EMR THz-NO.

The effect of $\mathrm{THz}$ waves on procoagulative potential was fixed only in the group of elderly patients (Table 1 ). An increase of ATR $(p<0.05)$ and decrease of fibrinogen concentration $(p<0.05)$ had been denoted till the end of the THz-therapy-NO course. The revealed change display that in this group of the patients there is a decrease of antithrombogenic potential of blood is caused by an effect as at first stages (ATR), as at final (fibrinogen) stages of clotting. Generally we can say that $\mathrm{THz}$ waves decrease an activity of natural procoagulants at elderly patients. There had not been noted statistically valid change in ATR and fibrinogen parameters in the group of the middle-aged patients till the end of the treatment course $(p>0.05)$ (Table 1). The dynamics of APTT had not been revealed in both groups (Table 1).

Table 1.The dynamics of hemocoagulation and fibrinolysis in the patients with angina in different age groups with the use of $\mathrm{THz}$-therapy- $\mathrm{NO}(\mathrm{M} \pm \mathrm{m})$

\begin{tabular}{|c|c|c|c|}
\hline \multirow[t]{2}{*}{ Parameters } & \multirow[t]{2}{*}{ Follow-up period } & \multicolumn{2}{|c|}{ Groups of persons with angina } \\
\hline & & $\begin{array}{l}\text { Middle age } \\
\quad(n=36)\end{array}$ & $\begin{array}{l}\text { Elderly age } \\
\quad(n=29)\end{array}$ \\
\hline \multirow[t]{2}{*}{ APTT } & Before treatment & $40.68 \pm 1.72$ & $39.42 \pm 2.41$ \\
\hline & After treatment & $43.90 \pm 2.26$ & $42.75 \pm 2.79$ \\
\hline \multirow[t]{2}{*}{ ATR } & Before treatment & $63.80 \pm 1.56$ & $64.0 \pm 1.83$ \\
\hline & After treatment & $65.70 \pm 1.70$ & $67.10 \pm 1.84 *$ \\
\hline \multirow[t]{2}{*}{ FG } & Before treatment & $3.60 \pm 0.10$ & $3.73 \pm 0.13$ \\
\hline & After treatment & $3.60 \pm 0.12$ & $3.40 \pm 0.14 *$ \\
\hline \multirow[t]{2}{*}{ AT-III } & Before treatment & $77.07 \pm 6.30$ & $67.10 \pm 13.30$ \\
\hline & After treatment & $93.85 \pm 4.17 *$ & $78.60 \pm 9.49$ \\
\hline \multirow[t]{2}{*}{$\mathrm{EF}$} & Before treatment & $9.05 \pm 0.48$ & $9.74 \pm 0.77$ \\
\hline & After treatment & $9.90 \pm 0.90$ & $8.13 \pm 0.81$ \\
\hline
\end{tabular}

* - difference with "before treatment" parameter is statistically valid $(p<0.05)$.

\section{Discussion}

In the presented study there had been denoted that THztherapy has a positive effect on clinical progression and hemocoagulative parameters in the patients with effort angina of III-IV f.c. of different age.

At the same time there were the results that displayed a relatively independent dynamics of parameters of hemocoagulative parameters and antianginal effect of $\mathrm{THz}-$ therapy-NO in the examined patients. A rapid relief of angina symptoms had been progressing equally in the middle-aged and elderly patients, and change in parameters of thrombogenic blood potency was significantly different.

In the middle-aged patients normalization of hemocoagulative parameters was caused by an increase of antithrombin-III activity up to its total recovery, there was not fixed an effect on procoagulative potential. In the group of elderly patients the $\mathrm{THz}$ therapy-NO effect was realized by a positive dynamics of natural procoagulants level, the exposure was as at first stages, as at final stages of clotting, which was evident from fibrinogen decrease in combination with prolonged ATR. There was not dynamics of antithrombin-III activity. Parameters of fibrinolysis activity did not differ under the THz-therapy-NO neither in the group I, nor in the group II.

An antianginal effect of EMR of THz-NO is the same in groups of the middle-aged and elderly patients with angina, the effect on a hemostasis system differs significantly. It is not possible to explain this positive clinical dynamics only by a normalization of hemocoagulation.

Taking into account a possible mechanism of THz waves' effect through the modulation of NO cycle [2], it appears that the variety of effect of THz-therapy-NO on hemostasis system parameters in the patients of the studied age groups can be connected with agerelated changes of some NO cycle components or NO-synthase activity.

In this case an integral index of EMR of THz-NO effect antianginal effect - can be realized through various mechanisms of microcirculation improvement and decrease of thrombogenic blood potency. The final result - rapid relief of angina symptoms is achieved by activating of different adaptation mechanisms, but is comparable independent from age.

\section{Conclusion}

1. THz-therapy of NO band has a positive effect on a clinical state and parameters of hemocoagulation of the middle-aged and elderly patients with angina.

2. An antianginal effect of THz-therapy-NO is evident in the patients with effort angina of III-IV f.c. independent from age.

3. Effect of THz waves on hemostasis system state in the middleaged patients is realized through the activation of anticoagulative blood potential up to its total recovery.

4. An improvement of hemocoagulation indices under the THztherapy-NO in the patients of elderly age is realized through a decrease of procoagulants level.

Conflict of interest: none declared.

\section{Reference}

1. Betsky OV, Krenitsky AP, Maiborodin AV. Biophysical effects of THzband and perspectives of progress in a new direction in biomedical 
technologies. Biomedical Radioelectronics 2003; (12): 3-6. [Article in Russian]

2. Kirichuck VF, Ivanov AN, Kulapina EG, Krenickiy AP, Mayborodin AV. Effect of Terahertz Electromagnetic Irradiation at Nitric Oxide Frequencies on Concentration of Nitrites in Blood Serum of Albino Rats under Conditions of Immobilization Stress. Bull Exp Biol Med 2011; 149(2): 174-176. (PMID: 21113484) (doi: 10.1007/s10517-010-0900-9)

3. Parshina SS. Clinical features of the use of THz-therapy-NO in the patients with angina. Biomedical Radioelectronics 2006; (1-2): 4-11. [Article in Russian]

4. Parshina SS, Kirichuk VF, Golovacheva TV, Afanasyeva TN, Tupikin VD, Krenitsky AP, Mayborodin AV, Lopatina NA. Electro-magnetic radiation of terahertz range, NO molecular specter frequencies, and coagulation hemostasis in patients with various angina forms. Cardiovascular Therapy and Prevention 2006; (4): 70-74. [Article in Russian]

5. Vodolagin AV. Features of DIC syndrome in patients with effort angina of high functional classes and optimizing of the treatment. Abstract of PhD dissertation, Saratov, 2008. [Text in Russian]

6. Parshina SS, Golovacheva TV, Afanasjeva TN, Glukchova NA, Potapova MV, Grizenger VR, et.al. Particularities of the hemodynamic effects of the terahertz therapy in patients with angina pectoris of both sexes. Biomedical Radioelectronics 2011; (8): 58-63. [Article in Russian]

Authors:

Svetlana S. Parshina - MD, D.Sc., Professor, Department of Therapy, Faculty training and retraining of specialits, Saratov State Medical University n.a. V.I. Razumovsky, Saratov, Russia;

Tatyana N. Afanasyeva - MD, PhD, Assistant, Department of Therapy, Faculty training and retraining of specialits, Saratov State Medical University n.a. V.I. Razumovsky, Saratov, Russia;

Tatyana V. Golovacheva - MD, PhD, Professor, Department of Therapy, Faculty training and retraining of specialits, Saratov State Medical University n.a. V.I. Razumovsky, Saratov, Russia;

Vyacheslav F. Kirichuk - MD, D.Sc., Professor, Head of Department of Normal Physiology n.a. I.A. Chuevsky, Saratov State Medical University n.a. V.I. Razumovsky, Saratov, Russia;

Alexadr V. Vodolagin - MD, PhD, Assistant, Department of Therapy, Faculty training and retraining of specialits, Saratov State Medical University n.a. V.I. Razumovsky, Saratov, Russia. 